\title{
Pengaruh Diameter Leher Resonator Helmholtz pada Alat Pemanen Energi Akustik (Acoustic Energy Harvester) Terhadap Daya Listrik yang Dihasilkan
}

\author{
Yuanita Fara Abdillah ${ }^{1}$, Ikhsan Setiawan, Agung B.S. Utomo \\ Departemen Fisika Matematika dan Ilmu Pengetahuan Alam, Universitas Gadjah Mada Sekip Utara \\ BLS 21, Yogyakarta 55281, Indonesia \\ 1Email : yuanita.fara.a@mail.ugm.ac.id
}

\begin{abstract}
Acoustic energy (sound) that is wasted in environment has potential to be alternative energy to produce electrical energy. This paper presents an experimental study of the effect of Helmholtz resonator neck diameter on the output electric power of an acoustic energy harvester. The cavity of the resonators is a cube-shaped with size of $30 \mathrm{~cm} \times 30 \mathrm{~cm} \times 30 \mathrm{~cm}$ made of acrylic. The resonator neck is cylindrical and has $8 \mathrm{~cm}$ length with four diameter variations of $5,2 \mathrm{~cm}, 6,9 \mathrm{~cm}, 8,2 \mathrm{~cm}$, and 10,4 cm. A 6-inches subwoofer loudspeaker is used as acoustic transducers that converts sound into electric current. The experiment is performed by giving sound with SPL of $90 \mathrm{~dB}$ in the frequency range of (20-150) $\mathrm{Hz}$. The output rms voltages from the loudspeaker are measured at a $5.0 \mathrm{ohm}$ load resistor. It is found that there are always two peaks in the frequency spectrum that provide maximum electric power, namely at $27 \mathrm{~Hz}$ and $55 \mathrm{~Hz}$. These peak frequencies do not depend on the neck diameter. On the other hand, the larger the neck diameter, the higher the generated electrical power. The highest rms electric power produced are $3.03 \mathrm{~mW}$ and $2.25 \mathrm{~mW}$ at the first and second peaks, respectively.
\end{abstract}

Keywords: Acoustic energy harvesting, loudspeaker, Helmholtz resonator, neck diameter

\begin{abstract}
Abstrak: Energi akustik (bunyi) yang terbuang di lingkungan memiliki potensi menjadi salah satu energi alternatif untuk menghasilkan energi listrik. Makalah ini memaparkan tentang studi eksperimental pengaruh diameter leher resonator Helmholtz pada alat pemanen energi akustik terhadap daya listrik yang dihasilkan. Rongga resonator Helmholtz berbentuk kubus berukuran $30 \mathrm{~cm}$ $\times 30 \mathrm{~cm} \times 30 \mathrm{~cm}$ terbuat dari akrilik. Leher resonator berbentuk silinder sepanjang $8 \mathrm{~cm}$ dengan empat variasi diameter yaitu $5,2 \mathrm{~cm}, 6,9 \mathrm{~cm}, 8,2 \mathrm{~cm}$, dan $10,4 \mathrm{~cm}$. Loudspeaker jenis subwoofer dengan diameter nominal 6 inci dipasang disisi belakang rongga resonator digunakan sebagai transduser akustik yang mengubah bunyi menjadi arus listrik. Eksperimen dilakukan dengan memberikan gelombang bunyi dengan SPL (sound pressure level) $90 \mathrm{~dB}$ dalam rentang frekuensi $(20$ - 150) $\mathrm{Hz}$ dan mengukur tegangan listrik rms keluaran dari loudspeaker pada resistor beban 5,0 ohm. Diperoleh bahwa selalu terdapat dua puncak spektrum frekuensi dengan daya listrik maksimum, yaitu pada 27 $\mathrm{Hz}$ dan $55 \mathrm{~Hz}$. Frekuensi-frekuensi puncak ini tidak bergantung pada diameter leher resonator. Di sisi lain, ditemukan bahwa diameter leher yang semakin besar menghasilkan daya listrik yang semakin besar. Daya listrik rms terbesar yang dihasilkan (pada diameter 10,4 cm) adalah 3,03 $\mathrm{mW}$ dan 2,25 $\mathrm{mW}$ masing-masing pada puncak pertama dan puncak kedua.
\end{abstract}

Kata kunci: pemanenan energi akustik, loudspeaker konversi, resonator Helmholtz, diameter leher resonator

\section{PENDAHULUAN}

Di indonesia saat ini populasi penduduk semakin meningkat membuat jumlah kebutuhan energi juga akan semakin meningkat. Khususnya energi listrik menjadi bagian yang tak terpisahkan. Sumber pembangkit listrik yang utama sekarang adalah bahan bakar fosil, dan diperkirakan akan habis 75 tahun lagi (Kholiq, 2015). Oleh karena itu diperlukan sumber energi alternatif dan terbarukan seperti energi air, angin, matahari, biomassa, bahkan nuklir. Belakangan ini para peneliti tertarik pada energi getaran dan energi akustik (bunyi) yang 
biasanya berupa kebisingan, ternyata juga memiliki potensi untuk menjadi salah satu alternatif energi sebagai konsekuensi dari hukum kekekalan energi (Wijanto dkk, 2018).

Pemanenan energi akustik (acoustic energy harvesting) dapat digambarkan sebagai proses konversi gelombang akustik yang intensitasnya tinggi dan terus menerus dari lingkungan menjadi energi listrik dengan menggunakan transduser akustik, resonator akustik, unit penyearah arus listrik, dan unit penyimpang energi listrik. Tingkat kebisingan bunyi atau sound pressure level $(S P L)$ dinyatakan dalam satuan desibel $(\mathrm{dB})$. Beragam kebisingan tersebut diantaranya berasal dari nada panggil telepon $(80 \mathrm{~dB})$, kebisingan jalan raya (80-90 $\mathrm{dB})$, peluit kereta $(90 \mathrm{~dB})$, bor tangan $(98 \mathrm{~dB})$, mesin sepeda motor dan mobil $(100 \mathrm{~dB})$, mesin pabrik dan konser musik $(120 \mathrm{~dB})$, mesin jet pesawat dari jarak 100 meter $(140 \mathrm{~dB})$, perangkat termoakustik sederhana (176 dB), granat setrum (170-180 dB), suara paling keras dan pesawat jet pada jarak 50 meter (194 dB) (Pillai dan Deenadayalan, 2014). Hal ini menunjukkan adanya peluang yang cukup potensial untuk memanfaatkan energi yang terbuang dan menggangu ini sebagai sumber energi alternatif yang ramah lingkungan. Meskipun energi listrik yang diperoleh dalam hal ini relatif kecil, energi listrik tersebut dapat diakumulasikan dalam unit penyimpan.

Transduser akustik (atau sering disebut juga generator) berfungsi sebagai pengubah gelombang bunyi menjadi arus listrik bolak-balik (alternating current, AC) (Hassan dkk, 2014). Sebagian besar transduser akustik yang digunakan dalam alat pemanen energi akustik (acoustic energy harvester) adalah material piezoelektrik. Resonator akustik berperan sebagai pengumpul energi akustik dari lingkungan melalui ujung yang terbuka. Ada dua jenis resonator yang biasa digunakan yaitu resonator Helmholtz dan resonator tabung lurus. Sebuah unit penyearah arus (rectifier atau $A C$ to $D C$ converter) digunakan untuk mengubah arus bolak-balik tersebut menjadi arus searah (direct current, $D C$ ) sebelum akhirnya disimpan di dalam sebuah unit penyimpanan energi listrik (energy storage) seperti baterai atau superkapasitor (Pillai dan Deenadayalan, 2014). Izhar dan Khan pada tahun 2018 mengembangkan alat pemanen energi akustik menggunakan resonator Helmholtz (berbentuk kerucut untuk menguatkan gelombang akustik yang masuk) dan pelat komposit pizoelektrik ditambah dengan balok kantilever. Balok kantilever yang digunakan terbuat dari kuningan, batang tembaga dan pelat baja yang melekat pada bagian tengah dari pelat komposit untuk memperluas bidang frekuensi sumber bunyi, dan menambah derajat kebebasan ke pemanen energi akustik (Izhar dan Khan, 2018).

Di sisi lain, loudspeaker juga dapat mengkonversi energi bunyi menjadi energi listrik. Dimastya (2018) telah melakukan penelitian tentang pembuatan dan pengujian alat pemanen energi akustik dengan komponen utama yang terdiri dari sebuah resonator Helmholtz dan sebuah loudspeaker konversi berjenis full range. Resonator Helmholtz terbuat dari kayu berbentuk kubus yang berukuran $46 \mathrm{~cm} \times 46 \mathrm{~cm} \times 46 \mathrm{~cm}$ dengan ketebalan dinding sebesar 2 $\mathrm{cm}$. Lubang leher resonator Helmholtz berbentuk lingkaran dengan diameter $6 \mathrm{~cm}$ yang dibuat di bagian tengah sisi depan rongga resonator. Di bagian belakang rongga resonator Helmholtz dipasang loudspeaker konversi yang digunakan untuk mengubah gelombang bunyi yang masuk ke dalam resonator Helmholtz melalui lehernya menjadi arus listrik. Pengujian dilakukan dengan menggunakan variasi panjang leher resonator sebesar $2 \mathrm{~cm}, 10 \mathrm{~cm}$ dan 20 $\mathrm{cm}$, dan juga variasi frekuensi dari $30 \mathrm{~Hz}$ sampai $200 \mathrm{~Hz}$ dan $S P L$ dari $65 \mathrm{~dB}$ sampai $100 \mathrm{~dB}$ untuk tiap panjang leher resonator. Nilai daya $r m s$ keluaran tertinggi, yaitu $2,35 \mathrm{~mW}$ diperoleh ketika panjang leher resonator $2 \mathrm{~cm}, S P L$ sebesar $100 \mathrm{~dB}$ dan frekuensi $41 \mathrm{~Hz}$.

Salah satu faktor yang mempengaruhi frekuensi resonansi resonator Helmholtz adalah diameter leher resonator (selain panjang leher dan volume rongga resonator). Oleh karena itu, dalam penelitian ini ingin dipelajari tentang pengaruh diameter leher resonator Helmholtz 
terhadap daya listrik rms yang dihasilkan oleh alat pemanen energi akustik yang menggunakan resonator Helmholtz.

\section{METODE PENELITIAN}

Penelitian ini dilakukan secara eksperimen di laboratorium. Resonator Helmholtz yang digunakan berbentuk kubus berukuran $30 \mathrm{~cm} \times 30 \mathrm{~cm} \times 30 \mathrm{~cm}$ terbuat dari bahan akrilik setebal $1 \mathrm{~cm}$ sudah tersedia di laboratorium. Penelitian ini memodifikasi sisi depan resonator Helmholtz dengan variasi diameter leher dan panjang leher tetap $8 \mathrm{~cm}$. Pemilihan diameter leher resonator Helmholtz didasarkan pada pipa $P V C$ yang tersedia di pasaran dipilih empat variasi diameter dari pipa $P V C$ merk Wavin tipe AW, seperti disajikan dalam Tabel 1.

Skema susunan peralatan eksperimen ditunjukkan oleh Gambar 1(a), sedangkan ilustrasi dinding depan resonator Helmholtz dengan variasi diameter (Dn) ditunjukkan oleh Gambar 1(b). Sumber bunyi yang digunakan adalah sebuah loudspeaker sumber dengan diameter nominal 15 inci yang dilengkapi dengan kotak-nya. Loudspeaker ini diberi sinyal audio oleh sebuah pembangkit sinyal audio (audio function genertor, $A F G$ ) GW-Instek model GFG8250A yang diperkuat oleh sebuah unit penguat audio (audio amplifier).

Tingkat kenyaringan bunyi yang diwakili oleh tingkat tekanan gelombang bunyi (sound pressure level, $S P L$ ) diukur menggunakan alat Lutron model SL-40, dinyatakan dalam satuan decibel $(\mathrm{dB})$ dengan nilai acuan $20 \mu \mathrm{Pa}$. Pada jarak $20 \mathrm{~cm}$ dari loudspeaker sumber, $S P L$ yang digunakan dalam eksperimen ini adalah $90 \mathrm{~dB}$. Pada eksperimen ini, loudspeaker pengkonversi yang digunakan harus disesuaikan dengan luas sisi rongga resonator Helmholtz, maka loudspeaker yang digunakan berukuran diameter nominal 6 inci berjenis subwoofer ditempatkan dibelakang resonator Helmholtz seperti tampak dalam skema pada Gambar 1(a).

Dalam eksperimen ini $S P L$ ditempatkan berdampingan dengan ujung terbuka resonator seperti Gambar 1(a). Bunyi dari loudspeaker sumber diterima oleh loudspeaker pengkonversi yang mengubahnya menjadi arus lisrik bolak-balik yang dilewatkan pada sebuah resistor beban dengan resistansi $R_{\mathrm{b}}=5 \mathrm{ohm}$. Tegangan rms (root-mean-squre) $V_{r m s}$ antara ujungujung resistor beban diukur dengan menggunakan sebuah multimeter digital Sanwa model RD700.

Tabel 1 Empat variasi diameter pipa $D_{n}$ sebagai leher resonator Helmholtz

\begin{tabular}{ccc}
\hline & \multicolumn{2}{c}{$D_{n}$} \\
\cline { 2 - 3 } & Nominal (inci) & Diameter-dalam $(\mathrm{cm})$ \\
\hline 1 & 2 & 5,2 \\
2 & $21 / 2$ & 6,9 \\
3 & 3 & 8,2 \\
4 & 4 & 10,4 \\
\hline
\end{tabular}




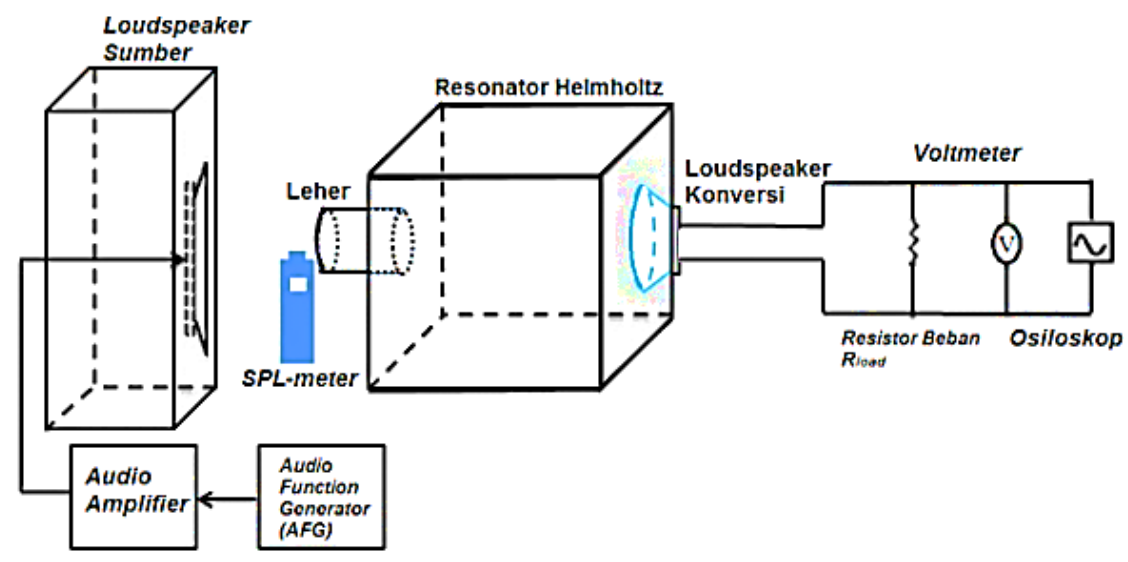

(a)

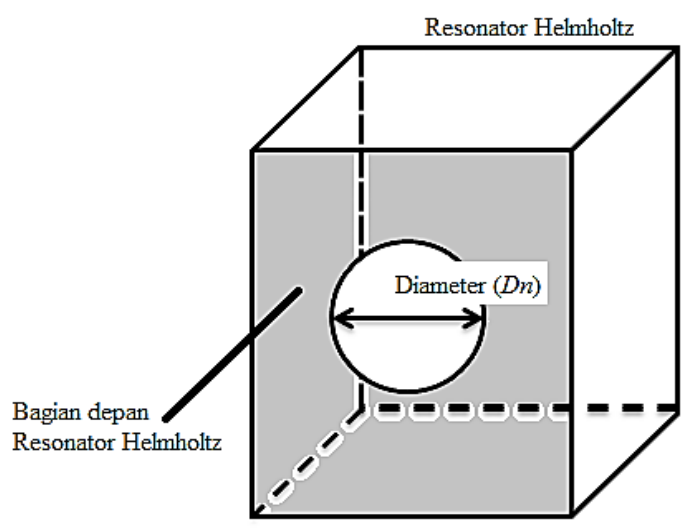

(b)

Gambar 1. Pemanenan energi akustik: (a) skema susunan peralatan eksperimen, (b) ilustrasi dinding depan resonator Helmholtz

Dalam resonator Helmholtz terjadi fenomena resonansi udara dalam ruang atau rongga yang berisi gas. Tekanan bunyi tertinggi dari rongga dihasilkan pada frekuensi resonansi yang ditentukan oleh dimensi volume rongga dan dimensi leher dari resonator akustik (Lee dan Choi, 2013). Frekuensi resonansi dari resonator Helmholtz $\left(f_{\mathrm{RH}}\right)$ dirumuskan sebagai berikut (Li dkk, 2017).

$$
f_{\mathrm{RH}}=\frac{v}{2 \pi} \sqrt{\frac{S}{V L_{e f f}}}
$$

dengan $v$ adalah cepat rambat gelombang bunyi di udara, $S$ adalah luas penampang leher resonator, $V$ adalah volume rongga resonator, dan $L_{\mathrm{ef}}$ merupakan panjang efektif leher resonator, yaitu

$$
L_{e f f}=L_{n}+1,7 r_{n}
$$

dengan $L_{n}$ dan $r_{n}$ berturut-turut adalah panjang leher dan jejari leher.

Eksperimen ini dilakukan dengan mengukur $V_{r m s}$ pada resistor beban untuk berbagai frekuensi bunyi mulai dari $20 \mathrm{~Hz}$ hingga $150 \mathrm{~Hz}$ dan dengan SPL tetap yaitu $90 \mathrm{~dB}$. Frekuensi 
bunyi diatur dengan menggunakan $A F G$, sedangkan $S P L$ diatur dengan menggunakan unit penguat audio dan dengan mengamati nilai $S P L$ pada sound level meter (SPL - meter) (Setiawan, 2019). Daya listrik rms yang dihasilkan oleh loudspeaker pengkonversi dihitung dengan menggunakan rumus

$$
P_{r m s}=\frac{V_{r m s}^{2}}{R_{\mathrm{b}}}
$$

\section{HASIL DAN PEMBAHASAN}

Hasil pengukuran $V_{r m s}$ pada alat pemanen energi akustik dalam penelitian ini yang dikenai gelombang bunyi dengan SPL $90 \mathrm{~dB}$ pada berbagai frekuensi dalam rentang $20 \mathrm{~Hz}-150 \mathrm{~Hz}$ diperlihatkan oleh Gambar 2(a)-(d). Tampak bahwa selalu memiliki dua puncak spektrum, dan puncak pertama selalu lebih tinggi dibandingkan dengan puncak kedua dan memiliki dua daerah operasional. Daerah operasional yang pertama berkisar dalam rentang frekuensi $24 \mathrm{~Hz}$ - $38 \mathrm{~Hz}$ dan daerah operasional yang kedua berada dalam rentang frekuensi $45 \mathrm{~Hz}-76 \mathrm{~Hz}$. Dalam daerah operasional tersebut terjadi fluktuasi daya listrik yang dihasilkan, dan terdapat 2 puncak sprektrum yang berkisar pada frekuensi $27 \mathrm{~Hz}$ dan $55 \mathrm{~Hz}$ (lihat Gambar 2).

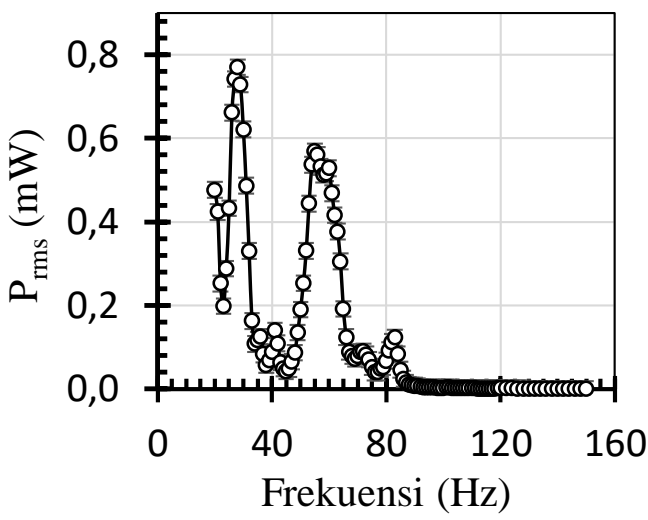

(a)

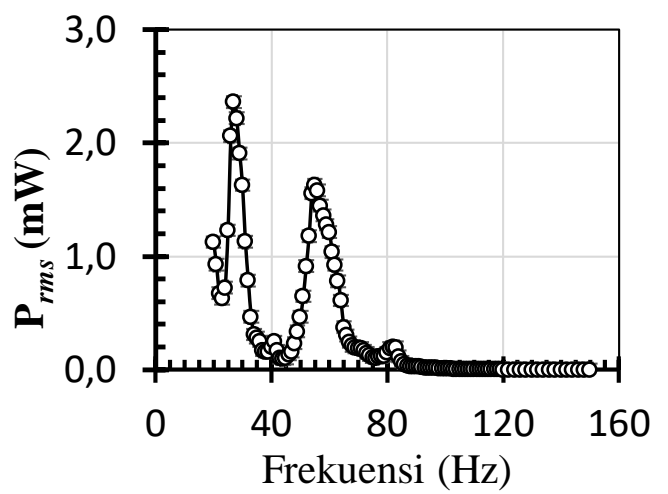

(c)

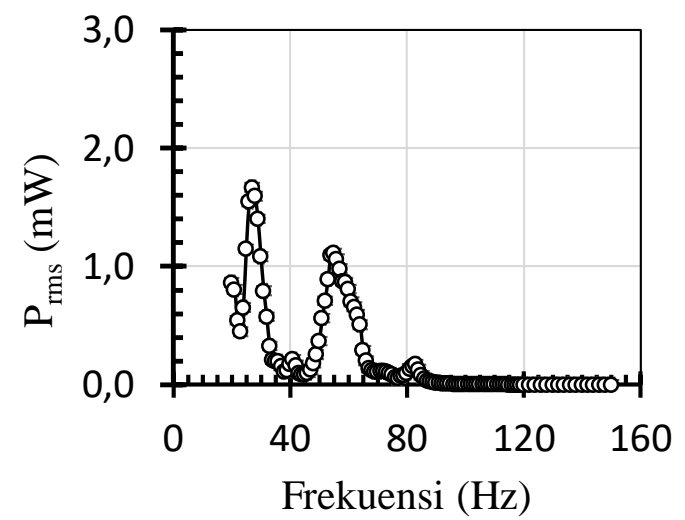

(b)

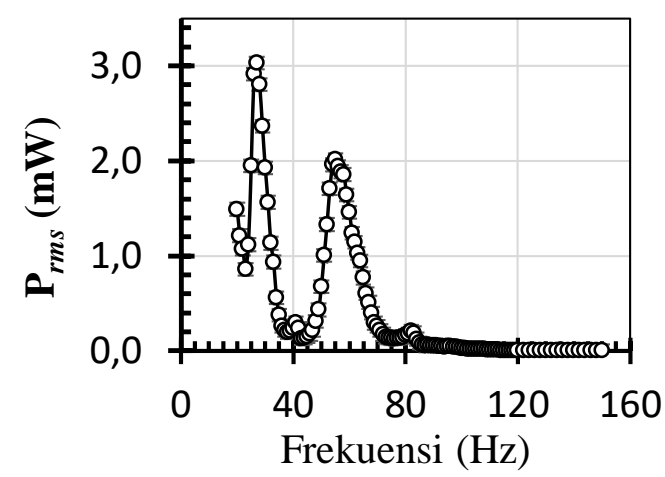

(d)

Gambar 2. Grafik hubungan daya listrik rms yang dihasilkan oleh alat pemanen energi akustik dengan frekuensi bunyi yang mengenainya pada $S P L$ tetap $90 \mathrm{~dB}$ untuk berbagai diameter dengan panjang leher tetap (a) diameter leher 5,2 cm, (b) diameter leher $6,9 \mathrm{~cm}$, (c) diameter leher $8,2 \mathrm{~cm}$, (d) diameter leher $10,4 \mathrm{~cm}$. 
Terkait puncak pertama, secara teori menggunakan rumus (1) resonator Helmholtz yang telah dibuat dengan variasi diameter dan dengan panjang leher tetap $8 \mathrm{~cm}$ dalam penelitian ini memiliki frekuensi resonansi sebesar $43 \mathrm{~Hz}$ untuk diameter 5,2 cm, $55 \mathrm{~Hz}$ untuk diameter 6,9 $\mathrm{cm}, 62 \mathrm{~Hz}$ untuk diameter 8,2 cm, dan $75 \mathrm{~Hz}$ untuk diameter 10,4 cm. Dengan menggunakan cepat rambat bunyi $346 \mathrm{~m} / \mathrm{s}$. Artinya frekuensi optimum yang diperoleh akan terus meningkat seiring dengan bertambahnya lebar diameter leher resonator. Frekuensi resonansi tersebut berbeda dengan frekuensi puncak spektrum $27 \mathrm{~Hz}$ (puncak pertama). Perbedaan ini dapat disebabkan oleh modifikasi sisi belakang resonator Helmholtz yang dipasang loudspeaker konversi. Seharusnya resonator Helmholtz berbentuk kubus tanpa ada loudspeaker konversi, loudspeaker konversi yang digunakan berdiameter 6 inci $(15,24 \mathrm{~cm})$ sedangkan sisi belakang resonator Helmholtz hanya berukuran $30 \mathrm{~cm} \times 30 \mathrm{~cm}$ sehingga sisi belakang resonator Helmholtz hampir terhalang oleh loudspeaker.

Terkait dengan puncak kedua, berdasarkan spesifikasi loudspeaker konversi yang digunakan yaitu ACR 6 inci C-630-Wh berjenis subwoofer, loudspeaker ini memiliki frekuensi resonansi sebesar $50 \mathrm{~Hz}$. Oleh karena itu dapat dipahami bahwa adanya puncak spektrum yang kedua (yaitu pada frekuensi sekitar $55 \mathrm{~Hz}$ ) berasal dari resonansi loudspeaker konversi yang digunakan.

Daya listrik rms yang dihasilkan pada puncak satu dan puncak dua untuk masing-masing diameter sebesar $0,77 \mathrm{~mW}$ dan $0,57 \mathrm{~mW}$ untuk diameter leher 5,2 $\mathrm{cm}, 1,67 \mathrm{~mW}$ dan 1,11 $\mathrm{mW}$ untuk diameter leher $6,9,2,36 \mathrm{~mW}$ dan $1,63 \mathrm{~mW}$ untuk diameter leher $8,2 \mathrm{~cm}, 3,03 \mathrm{~mW}$ dan 2,01 $\mathrm{mW}$ untuk diameter leher 10,4 cm. Adapun terdapat 2 puncak kecil dengan daya listrik rms rendah di sekitar frekuensi $41 \mathrm{~Hz}$ dan 82. Selanjutnya daya listrik rms yang dihasilkan pada frekuensi $86 \mathrm{~Hz}-150 \mathrm{~Hz}$ cenderung konstan dan sangat kecil sehingga dapat diabaikan. Daya listrik rms tertinggi yang dihasilkan yaitu pada diameter leher $10,4 \mathrm{~cm}$ sebesar 3,03 $\mathrm{mW}$ dan 2,01 $\mathrm{mW}$ (lihat Gambar 3 dan Gambar 4). Hal ini dikarenakan tingginya nilai daya listrik rms (Prms) tergantung pada besarnya diameter leher resonator Helmholtz yang digunakan. Semakin lebar diameter leher sisi depan resonator Helmholtz maka gelombang bunyi dari sumber kebisingan yang masuk menuju resonator Helmholtz semakin meningkat sehingga daya listrik rms yang dihasilkan juga semakin besar.

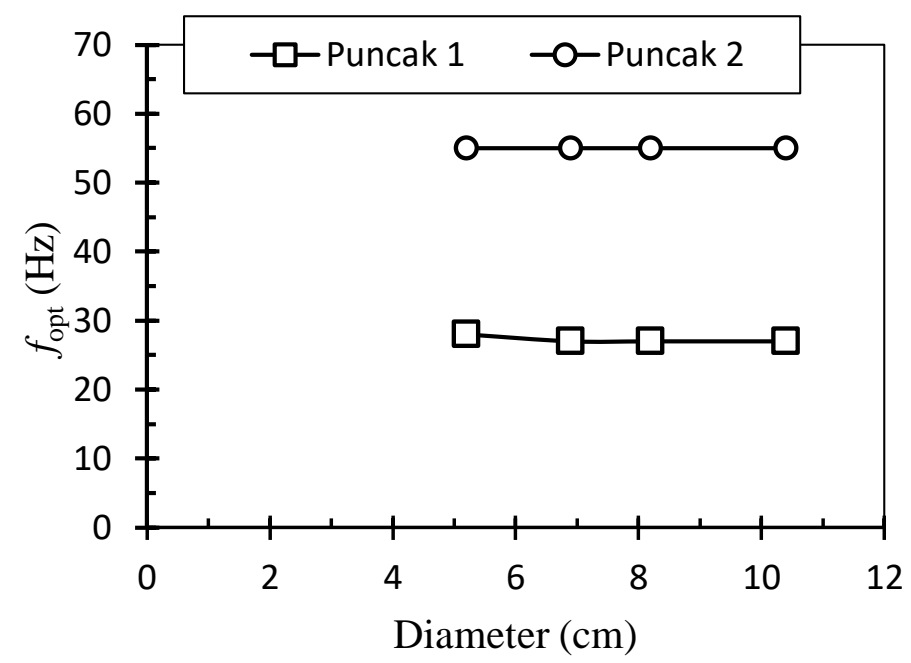

Gambar 3. Grafik hubungan antara frekuensi optimum $\left(f_{\text {opt }}\right)$ dengan dengan berbagai macam diameter yang berbeda. 


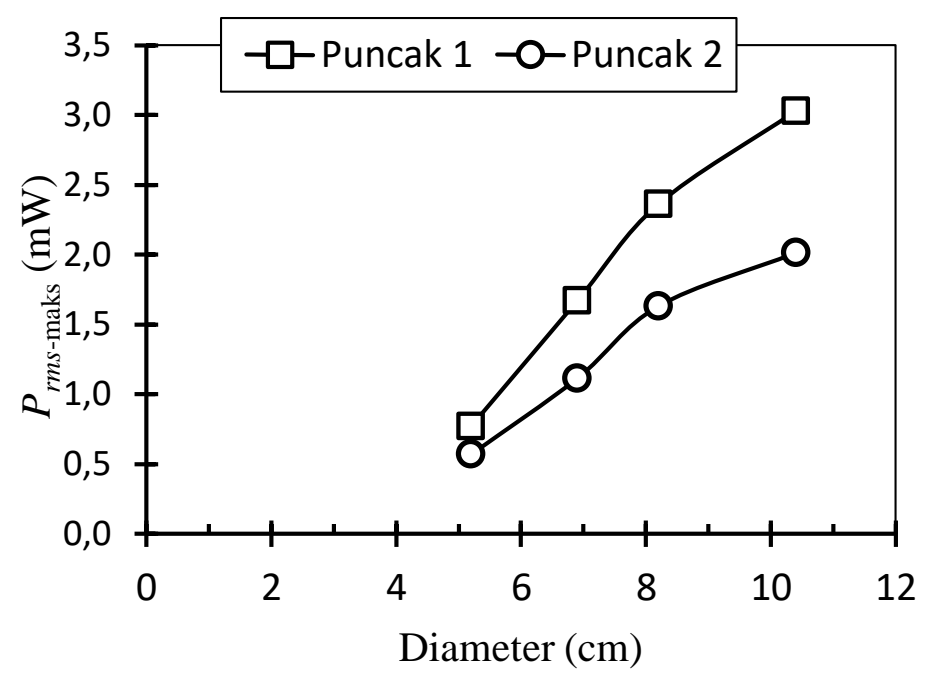

Gambar 4. Grafik hubungan antara daya listrik keluaran dengan berbagai macam diameter yang berbeda.

\section{KESIMPULAN}

Hasil eksperimen dalam penelitian ini menggunakan resonator Helmholtz dan loudspeaker konversi berjenis subwoofer menunjukkan bahwa terdapat dua daerah frekuensi bunyi operasional yang menghasilkan daya listrik rms relatif besar. Daerah operasional yang pertama terletak dalam daerah frekuensi sekitar $27 \mathrm{~Hz}$ dan terkait dengan resonansi resonator Helmholtz, sedangkan daerah operasional kedua terletak dalam frekuensi sekitar $55 \mathrm{~Hz}$ dan terkait dengan resonansi loudspeaker konversi yang digunakan. Variasi diameter dengan panjang leher tetap $8 \mathrm{~cm}$ pada alat pemanen energi akustik ini menghasilkan daya listrik yang tinggi pada diameter 10,4 cm. Daya listrik yang dihasilkan sebesar 3,03 $\mathrm{mW}$ untuk puncak pertama dan 2,01 $\mathrm{mW}$ untuk puncak kedua. Daya listrik $r m s\left(P_{\mathrm{rms}}\right)$ bergantung pada besarnya diameter leher resonator Helmholtz yang digunakan. Semakin lebar diameter leher sisi depan resonator Helmholtz maka gelombang bunyi dari sumber kebisingan yang masuk menuju resonator Helmholtz semakin meningkat sehingga daya listrik loud yang dihasilkan juga semakin besar.

\section{SARAN}

Menambah variasi diameter untuk melanjutkan penelitian ini, untuk mengetahui apabila diameter leher diperbesar daya listrik rms yang dihasilkan semakin meningkat atau menurun. Memodifikasi penempatan loudspeaker konversi pada sisi samping resonator Helmholtz dan menambah jumlah loudspeaker konversi menjadi tiga sisi. Mengganti loudspeaker konversi menggunakan mikrofon untuk mengetahui perbedaannya dan mendapatkan hasil yang lebih efektif.

\section{DAFTAR PUSTAKA}

Dimastya, R. A., 2018, Pembuatan dan Pengujian Alat Pemanen Energi Akustik (Acoustic Energy Harvester) Menggunakan Loudspeaker dan Resonator Helmholtz Sebagai Sumber Energi Alternatif, Skripsi, Fakultas Matematika dan Pengetahuan Alam, Universitas Gadjah Mada.

Hassan, F.H., Idris, Syed, S.H. dan Rahim, R.A., 2014, Acoustic Energy Harvesting Using Piezoelectric Generator for Low Frequency Sound Waves Energy Conversion, 
International Journal of Engineering and Technology (IJET), 5, 6, 4702-4707.

Izhar dan Khan, F. U., 2018, Three Degree of Freedom Acoustic Energy Harvester Using Improved Helmholtz Resonator, International Journal Of Precision Engineering And Manufacturing, 1, 19, 143-154.

Kholiq, I., 2015, Pemanfaatan Energi Alternatif Sebagai Energi Terbarukan Untuk Mendukung Substitusi BBM, Jurnal IPTEK, 19, 2, 82-83.

Lee, H. Y. dan Choi, B., 2013, A Study on the Acoustic Energy Harvesting with Helmholtz Resonator and Piezoelectric Cantilevers, Smart Materials and Structures, 22, 1-12.

Li, L., Liu, Y., Zhang, F. dan Sun, Z., 2017, Several Explanation on the Theoretical Formula of Helmholtz Resonator, Elseveir.

Pillai, M.A. \& Deenadayalan, E. 2014. A Review of Acoustic Energy Harvesting. International Journal of Precision Engi-neering And Manufacturing, Vol. 15 No. 5, hal. 949-965.

Setiawan, I, 2019, Studi Eksperimental Penggunaan Loudspeaker Sebagai Pengkonversi Energi Bunyi Menjadi Listrik Dalam Alat Pemanen Energi Akustik (Acoustic Energy Harvester), Jurnal Teknologi Vol.11 No. 1, hal. 9-16.

Wijanto, E., Harsono, B., Renandy, R., Septian, A. dan Sutanto, K., 2018, Pengujian Sistem Konversi Energi Suara menjadi Energi Listrik menggunakan Piezoelektrik, ResearchGate. 